\title{
Are electric vehicles eco-friendly products? A review from life cycle and sustainability perspective
}

\author{
Niculina Alexandra Grigore ${ }^{1,}$, and Claudiu Vasile Kifor ${ }^{1}$ \\ ${ }^{1}$ Lucian Blaga University of Sibiu, Faculty of Engineering, 10 Victoriei Bvd., 550024 Sibiu, \\ Romania
}

\begin{abstract}
Industry, especially the automotive industry is permanently changing and adapting to the external and internal factors. The appearance of the new types of vehicles - electric vehicles, is a big and important step not only regarding the evolution of the product, but also regarding the advantages of reducing environmental impact. It is promoted the idea that an electric vehicle generates less direct emissions in use phase compared with a conventional one. If we limit to this, we could say that we are dealing with an eco-friendly type of vehicle. The question is, can we extend this idea to the other stages of the life cycle? What about the sustainability of the industry? This article highlights the methods of environmental impact assessment used by researchers for electric vehicles in terms of life cycle and sustainability. The findings of this systematic review demonstrate that even if are a large number of articles addressing electric vehicles, only a small number of them evaluate the electric vehicle from life cycle and sustainability point of view.
\end{abstract}

\section{Introduction}

In a world with limited resources, sustainability has become a key concept nowadays in carrying out any type of activity. It is well known that the development of any type of activity has a significant impact on the environment. [1] Taking into account the mentioned aspects, it appeared the need to approach this research topic in order to highlight the impact of electric vehicles on the environment taking into account the life cycle assessment. Outlining new issues is a step forward for decision-makers involved in improving environmental protection performance, as well as finding new sustainable solution.

This topic is interesting to address due to the complexity of the field and the fact that it enjoys a great interest at international level. Another determining factor is that the topic is up to date, the appearance of electric vehicles being relatively new, and the automotive industry is on an upward slope in the manufacture and sale of electric vehicles, which is why it is necessary to investigate how it influences this transformation of the automotive

*Corresponding author: alexandra.grigore@ulbsibiu.ro 
industry different areas of interest, including that of environmental protection. This contribution can be useful to several groups of interest: vehicle manufacturers by broadening their horizons in order to reduce the impact on the "targeted" environment in phases that require increased attention, regulators - the new results can be a support for the creation of programs and legislative projects which can come both in support of producers and consumers, as well as in support of other actors involved - waste collection companies, treatment, recycling companies. Last, but not least, consumers - by increasing awareness of opting for eco-friendly products. In order to live in a sustainable mother nature is foremost to understand the effect of our actions and to estimate on long term perspective the impact on environment.

Environmental regulations in the European Union are consistent with both changes in the automotive industry, being beneficial in directing manufacturers to innovation and adaptation in advance to the need to reduce emissions. According to studies conducted by the European Commission, it is found that electric vehicles have taken over and it is considered that by 2050 the European market will be fully electrified - in terms of selling electric vehicles. Given this radical change, it is necessary to evaluate new vehicles developed or under development at all stages of the life cycle. It is also necessary to provide a review of current green practices in the automotive industry regarding the reuse and recycling strategies used by car manufacturers. Separating the environmental impact by sectors throughout the life cycle stages allows decisions to be made in order to improve environmental performance where the impact is greatest. [2] Global urbanization models are a challenge through the damage facing the planet and the automotive industry is forced to constantly adapt and be in a continuous process of innovation. According to [3], it is considered that the flying car is a future today and electric cars will be a common car in the next 5-10 years.

\section{Literature review}

The scholars have been interested over time in the environmental impact of electric vehicles and have adopted various assessment methods to highlight more clearly their effects.

Table 1 represents a centralization of these methods adopted in recent research. This centralization can be a starting point for identifying new methods to highlight the impact on the environment. Due to life cycle assessment importance, the centralization includes also which phase is analyzed from the studies. In accordance with ISO 14040, the stages are divided in: a) raw materials, b) production, c) use stage and d) end-of-life. In order to take into account the life cycle within the implemented systems, the current ISO 14001 standard includes the approach from this perspective. Thus, along the logistics chain, companies that implement an environmental management system following the requirements of ISO 14001 must consider the perspective of the life cycle of products, services and activities that they can influence or control. The methodologies adopted by the scientific community used to capture and identify the impact of new vehicles on the environment are diverse. According to [4] it is considered that life cycle assessment (LCA) methodology for automotive industry systems started in 1970s and over time interest in its use has grown due to the desire to develop eco-efficient and sustainable products. In [5], life cycle sustainability assessment (LCSA) is considered a new approach that represent a transition from LCA, LCSA being a concept that was used mainly in the period 2010-2020. Also, following a wide variety of studies, it was concluded that most of the papers using LCSA, focused on a conceptual and methodological analysis, being a limited number of studies in which this methodology was used in a real case study. The use of methodologies to pursue an assessment of the automotive industry that takes into account both sustainability and the life cycle is a challenge due to the vastness of the subject and industry [5]. 
Table 1. Methods used for assessing the contributions to sustainability for electric vehicles

\begin{tabular}{|c|c|c|c|}
\hline $\begin{array}{l}\text { Assessment } \\
\text { method }\end{array}$ & $\begin{array}{l}\text { Brief description of the method for the } \\
\text { study }\end{array}$ & $\begin{array}{l}\text { Author } \\
\text { and } \\
\text { studies }\end{array}$ & $\begin{array}{l}\text { Life cycle } \\
\text { stages }\end{array}$ \\
\hline $\begin{array}{l}\text { Multi criteria } \\
\text { decision making } \\
\text { (MCDM) }\end{array}$ & $\begin{array}{l}\text { It is a new method used for best charging } \\
\text { station selection in order to satisfy the } \\
\text { decision maker. The problem includes many } \\
\text { conflicting and both tangible and intangible } \\
\text { criteria }\end{array}$ & [6] & $\begin{array}{l}\text { Usage } \\
\text { phase }\end{array}$ \\
\hline $\begin{array}{l}\text { Material flow } \\
\text { analysis (MFA) }\end{array}$ & $\begin{array}{l}\text { It is a systematic assessment based on the } \\
\text { principle of the conservation of matter. It } \\
\text { connects the sources, the pathways, and the } \\
\text { intermediate and final sinks of a material }\end{array}$ & [7] & All stages \\
\hline $\begin{array}{c}\text { Life cycle } \\
\text { assessment (LCA) }\end{array}$ & $\begin{array}{l}\text { It is a systematic assessment used to assess } \\
\text { the overall environmental impacts of a } \\
\text { product or service by including all direct and } \\
\text { indirect emissions. Has become a dominant } \\
\text { methodology in research studies concerning } \\
\text { sustainable development of a product }\end{array}$ & $\begin{array}{c}{[4],[7],[8],} \\
{[9],}\end{array}$ & All stages \\
\hline $\begin{array}{l}\text { Multiregional } \\
\text { input-output } \\
\text { based LCA } \\
\text { (MRIO) } \\
\end{array}$ & $\begin{array}{l}\text { It allows broadening the scope of system } \\
\text { boundary and allows estimating the life cycle } \\
\text { impact at a global scale. }\end{array}$ & [10] & All stages \\
\hline $\begin{array}{l}\text { Life cycle } \\
\text { sustainability } \\
\text { assessment }\end{array}$ & $\begin{array}{l}\text { It is including the } 3 \text { dimensions of } \\
\text { sustainability: environmental, social and } \\
\text { economic. LCSA is quantifying the } \\
\text { sustainability impact considering also the } \\
\text { product/service life cycle. }\end{array}$ & {$[5],[11]$} & All stages \\
\hline $\begin{array}{l}\text { Transition to } \\
\text { Electric Cars } \\
\text { using the } \\
\text { Consumat Agent } \\
\text { Rationale } \\
\text { (STECCAR) } \\
\end{array}$ & $\begin{array}{l}\text { It is a social simulation method based on the } \\
\text { Consumat approach }\end{array}$ & [12] & $\begin{array}{l}\text { Usage } \\
\text { stage }\end{array}$ \\
\hline $\begin{array}{l}\text { Protection Action } \\
\text { Decision Model } \\
\text { (PADM) }\end{array}$ & $\begin{array}{l}\text { It is a model used for risk adaptive } \\
\text { behavioural intentions for situations such as } \\
\text { natural disasters and environmental hazards. }\end{array}$ & [13] & All stages \\
\hline
\end{tabular}

\section{Electric vehicles life cycle}

New types of vehicles represent long-term challenges for environmental protection and the systems must be adapted in order to be functional and in line with the new components included in the vehicles. The economic and legislative environment adapted and understood the needs for mobility transition. At first glance, it relies heavily on reducing the impact on the environment through new technologies proposed by manufacturers in the industry, but it is necessary to think on long term about the methods used in end-of-life stages to be also eco-friendly.

The magnitude of the entry on the European market of electric vehicles can be seen in Figure 1. In the period 2010-2020, a rapid increase in sales of electric vehicles on the European market can be observed and the trend seems to continue similarly for the future according to different predictions. According to one prediction made in 2017 by Boston Consulting Group, a combination of hybrid and fully electric engines will reduce the global market share of pure internal combustion engines (ICE) by about $50 \%$ by 2030 [10]. 
According to [14], it is estimated that until 2030 will be recycled 120 thousand batteries and until 2040 a number of 1.8 million batteries. Those changes in automotive industry will bring further other changes which should be evaluated more closely to find the most appropriate solutions for assessing and reducing the impact on the environment.

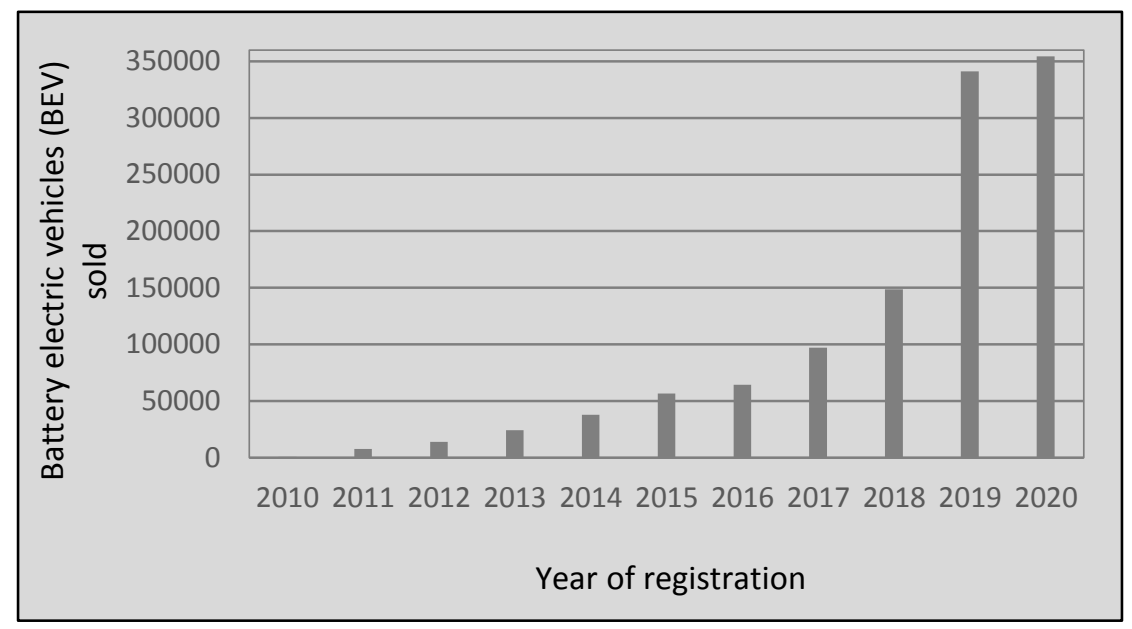

Fig. 1. Electric cars registered in the European Union, including Iceland, Norway and the United Kingdom (adapted according to Environment European Agency data) [15].

\section{Publication analysis from WoS}

This study is a systematic review analysis of electric vehicle research from a life cycle and sustainability perspective and this type of research allows us to make a classification of a number of studies and to establish their trend. The purpose of the paper is to make a descriptive-quantitative analysis to cover this specific theme [16].

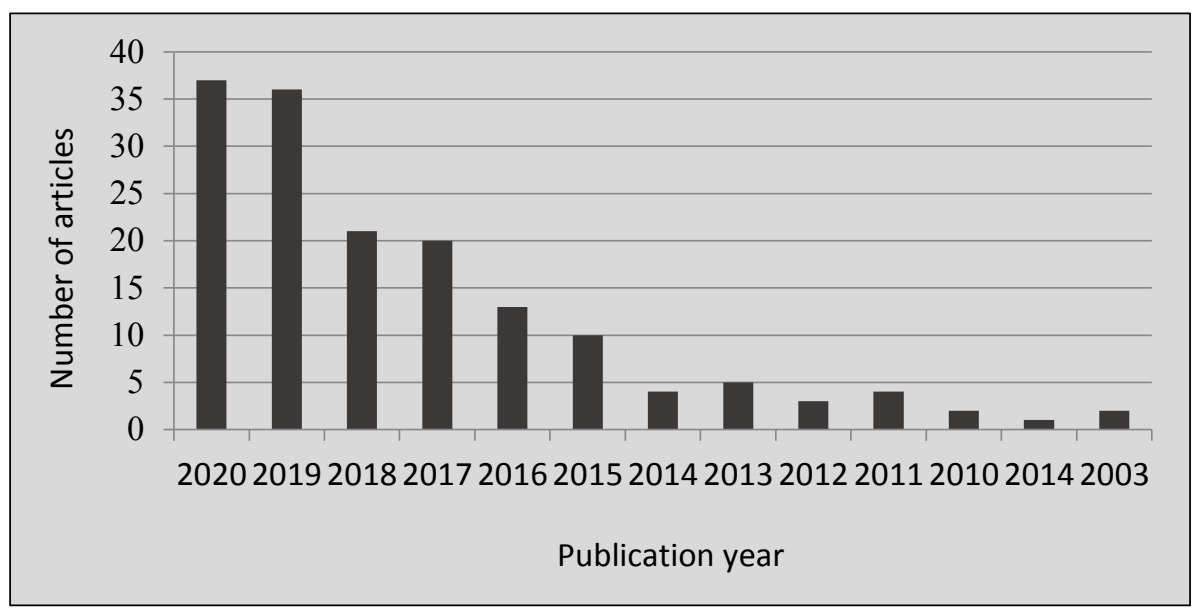

Fig. 2. Evolution of articles published containing the keywords electric vehicle, sustainability and life cycle (query made in 19.01.2021).

Material collection was done by searching studies on Web of Science core collection, one of the most comprehensive scientific databases, using the keywords: electric vehicle, 
sustainability and life cycle. First step was the selection of the field automotive area, especially focusing on environmental impact of electric vehicle from sustainable and life cycle perspective. The database returned 205 documents as result. From them, have been selected the articles and reviews until the end of 2020 and final result consisted in 158 studies. Mostly of them are recent ones, as it can be seen in Figure 2 and more than $72 \%$ of them are published in the last 4 years. This trend is auspicious because it has the role of showing and analyzing new types of vehicles from an environmental perspective. Current research has the opportunity to inspire the production companies in order to develop products and services favorable to our mother nature.

As a result, the link between those terms was more often in the last 4 years, this showing an increased interest on studies regarding electric vehicle impact on environment based on sustainable point of view, even if are some articles talking about electric vehicles older than 30 years. Starting with 2013 are more than 1000 articles/year regarding electric vehicle concept. Separately analyzed, it is curious to see that the concepts selected are mentioned in a big number of studies, but in only 25 articles is a link between the 4 th concepts.

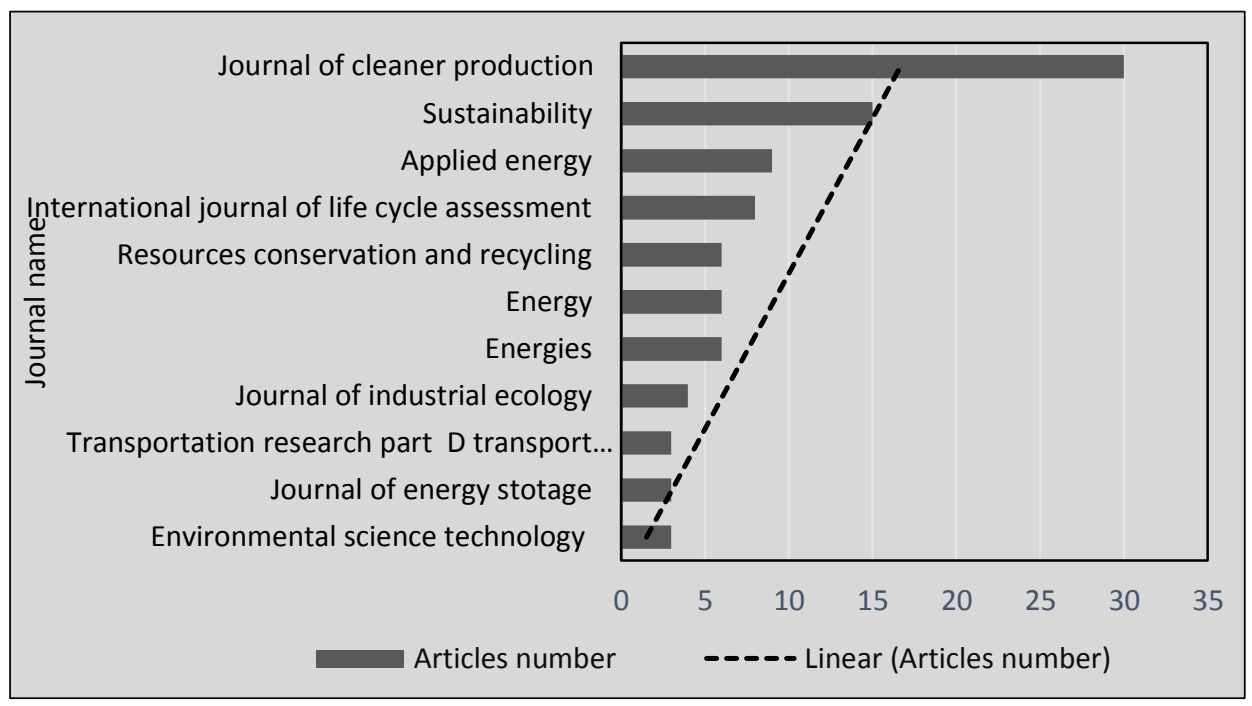

Fig. 3. Distribution of published articles per Journal (journals with more than 2 articles published).

According to Figure 3, analyzed by journal names, it can be observed that environmental protection is the predominant topic of the studies. More than $25 \%$ is represented by Journal of cleaner production (18\%) followed by Sustainability ( $9 \%)$.

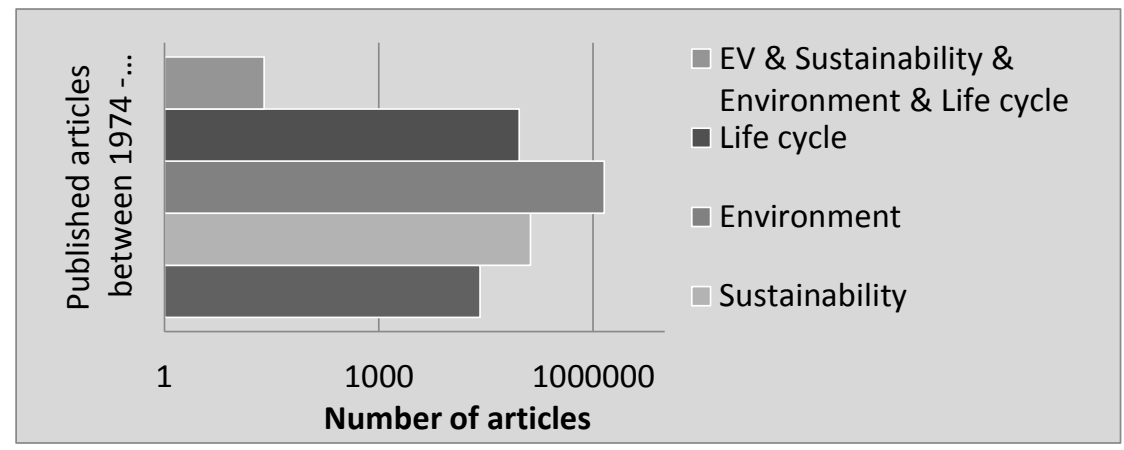

Fig. 4. Published articles between 1974 - 2020 containing the keywords defined (logarithmic scale). 
In Figure 4 it is represented the total number of the studies about the concepts analyzed separately and the number of studies that treated the electric vehicles in terms of environment, sustainability and life cycle. Because of a huge variation, the representation is made by using a logarithmic scale. It is also interesting to see that it is an increasing number of the studies over time starting with 1974 and 1975 when it is for the first time the keywords were mentioned in the WoS studies.

Because of the huge diversity of the studies regarding the concept, it is more representative to see the link between the concept EV, life cycle and sustainability in report with environmental protection. That is why a graphical representation with the number of articles refined together with the concept environmental protection is useful to understand the variation.

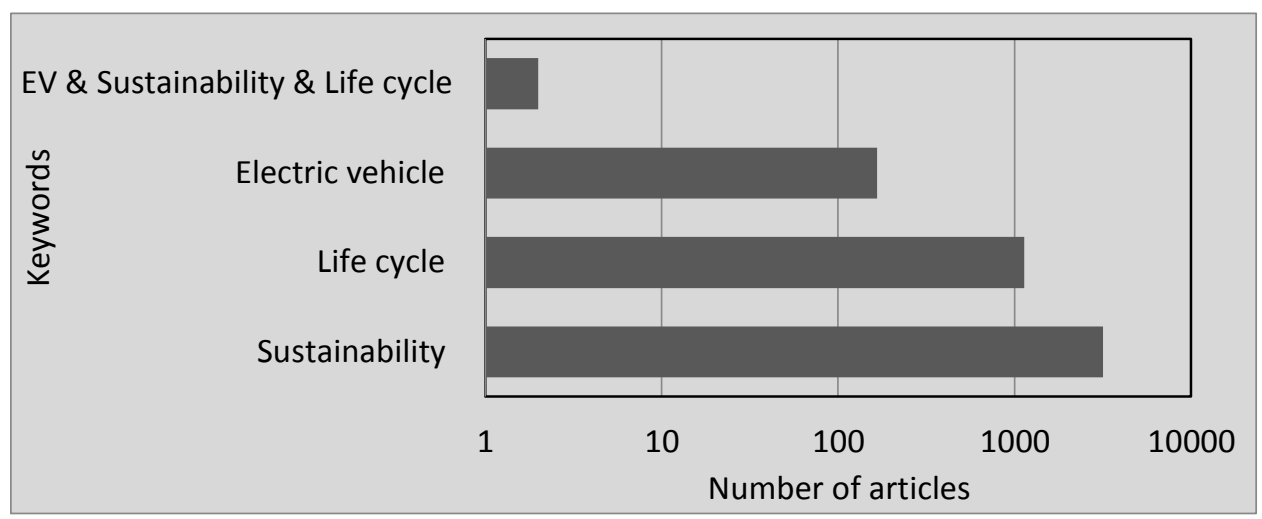

Fig. 5. Number of articles published in WoS refined in report with environmental protection (logarithmic scale).

According to Figure 5 it can be seen a small number of studies with all the keywords integrated (only 25 studies). That is why it is recommended a bigger focus on the field, in order to highlight new perspective about automotive industry, especially about electric vehicle.

\section{Results and discussion}

This study aims to highlight the degree of analysis of electric vehicles over time and how much previous research focused on identifying their impact on the environment. This part of the study is presenting the specific findings and the limitations. Results show an increased interest in the topic in recent years due to several directions and research needs. Electric vehicles industry is growing more and more and scientific community is paying attention to them not only from production point of view, but also from eco-friendly initiatives. There are mentions of electric vehicles in studies in the WoS Core Collection since 1975, when they were seen as cars of the future. Now everything is palpable, we use electric vehicles in everyday life, and the increase in their use is demonstrated by the increase in sales. Large vehicle manufacturers are confident that electric vehicles have a positive effect on the environment by reducing the impact. The scientific community has turned its attention to this topic, which is confirmed by publications that are based on a link between the electric vehicle industry and the environment more and more increased lately.

Although much research has been done over the years on electric vehicles, environmental protection and sustainability, it is interesting to note that an analysis of electric vehicles from the perspective of sustainability and life cycle has only recently been 
addressed. Through the analysis performed according to the present study, it will provide a basis for the need to integrate the concepts in future studies.

Limitations are represented by research criteria by selecting the specific keywords. Even if according to the results only 25 studies focus specifically on the link between the keywords, it is necessary to mention that the selection is very restrictive. The results do not include studies that touch tangentially or partially on the subject. Another limitation is because the present work did not focus on the study of the components of the electric vehicle, for example the battery, from the perspective of the life cycle and durability.

\section{Conclusions}

The evolution and separation of new consumer products has both advantages and disadvantages. In terms of electric vehicles, among the advantages identified by researchers in terms of environmental protection is the considerable reduction in global fuel consumption in the use phase, which leads directly to reducing emissions. A disadvantage is the complex activities in the automotive industry that are difficult to assess and control. It is important to assess the overall impact of these types of vehicles at all stages of the life cycle to conclude whether the activities and evolution of the industry has led to a impact reduction. Also, a classification of this impact in terms of severity would allow researchers to focus on areas that require a comprehensive assessment in order to find effective solutions for environmental protection.

Therefore, increasing the level of research in the industry in terms of life cycle and sustainability could lead to the identification of gaps in the systems, which is beneficial by providing the opportunity to act by taking actions. Also, regarding the 3 directions of sustainability (Economic, Environmental, Social) it is necessary a bigger focus on environmental side.

The battery, a key component for electric vehicles, is a challenge for the industry, through the necessary changes to be implemented. Although sales of electric vehicles are at the beginning of the road, predictions about the creation of efficient systems for the end-oflife stage of the vehicle and especially the battery are important and necessary in order not to create difficulties in the near future.

The revision of the legislation in a feasible way will be possible based on certain results of research on this topic.

Project financed from Lucian Blaga University of Sibiu, The Research centre for sustainable products and processes \& Hasso Plattner Foundation research action LBUS-RRC-2020-01.

\section{References}

1. Capgemini Research Institute, The Automotive Industry in the Era of Sustainability Executive summary, https://www.capgemini.com/wp-content/uploads/2020/03/The-Automotive-Industryin-the-Era-of-Sustainability.pdf (2020)

2. Ș. Guga, Industria auto, incotro? Tendinţe globale, perspective periferice (Friedrich-EbertStiftung, Bucharest, 2018)

3. V. Ciovirnache, D. Severa, Scientific Bulletin of the Politehnica University of Timisoara, Romania 5, 1 (2019)

4. L. L. P. de Souza, E. E. S. Lora, J. C. E. Palacio, M. H. Rocha, M. L. G. Renó, O. J. Venturini, J. Clean. Prod. 203, 444-468 (2018)

5. N. C. Onat, M. Kucukvar, O. Tatari, Sustainability 6, 12 (2014)

6. A. Karaşan, İ. Kaya, M. Erdoğan, Neural Comput. Appl. 32, 9 (2020)

7. S. Chen, Z. Lian, S. Li, J. Kim, Y. Li, L. Cao, Z. Liu, Energies 10, 12 (2017) 
8. I. Evtimov, R. Ivanov, H. Stanchev, G. Kadikyanov, G. Staneva, Transp. Probl. 15, 3 (2020)

9. H. Ambrose, A. Kendall, J. Ind. Ecol. 24, 1 (2020)

10. X. Mosquet, H. Zablit, A. Dinger, M. Andersen, The Electric Car Tipping Point (BCG, 2018)

11. N. C. Onat, M. Kucukvar, N. N. M. Aboushaqrah, R. Jabbar, Appl. Energy 250, 461-477 (2019)

12. A. Kangur, W. Jager, R. Verbrugge, M. Bockarjova, J. Environ. Psychol. 52, 166-182 (2017)

13. Y. Liu, Z. Ouyang, P. Cheng, J. Environ. Psychol. 64, 30-38 (2019)

14. M. Abdelbaky, J. R. Peeters, J. R. Duflou, W. Dewulf, Procedia CIRP 90, 432-436 (2020)

15. European Environment Agency, Monitoring of CO2 emissions from new passenger cars Regulation (EU) No 2019/631 (2019)

16. R. Merli, M. Preziosi, A. Acampora, J. Clean. Prod. 178, 703-722 (2018) 